\title{
¿DÓNDE PINTAR? UN ANÁLISIS COMPARATIVO MEDIANTE SIG COMO APROXIMACIÓN A LAS DECISIONES HUMANAS
}

LUCÍA A. MAGNIN*

\section{RESUMEN}

La localidad La Primavera (provincia de Santa Cruz, Argentina), fue ocupada por grupos cazadoresrecolectores móviles desde el Holoceno temprano al tardío (ca. 9.500-940 AP). En estudios previos, la distribución de evidencias arqueológicas en este sector fue analizada mediante sistemas de Información Geográfica (SIG) con la finalidad de estudiar aspectos de la movilidad y el uso diferencial del espacio. De este modo fue posible detectar recurrencias en la localización de distintos tipos de evidencia y una serie de factores ambientales.. En el caso de los lugares con arte rupestre, su localización se encuentra condicionada por la presencia de soportes rocosos adecuados en cuevas y aleros cuya existencia está determinada por la geomorfología local. Es por eso que para profundizar los conocimientos acerca de las decisiones humanas y los procesos de producción en el contexto del paisaje, es necesario analizar antes la disponibilidad natural de los soportes rocosos adecuados para pintar. El presente trabajo se propone abordar este problema comparando localizaciones de cuevas que presentan arte rupestre con otras que no presentan arte a pesar de contar con soportes y poseer buenas condiciones para la preservación de pinturas.

Los resultados obtenidos no alcanzan una significación estadística, pero muestran tendencias que permiten plantear como hipótesis que las cuevas elegidas para realizar pinturas serían aquellas más cercanas a recursos como las aguadas, las fuentes de aprovisionamiento de rocas útiles para la talla, y de ocre para confección de pinturas. A su vez, los espacios escogidos se encontrarían más cerca de las vías de movilidad del paisaje y presentarían cuencas visuales más amplias.

PALABRAS CLAVE: arte rupestre, SIG, cazadores-recolectores, Patagonia argentina.

\section{WHERE TO PAINT? A COMPARATIVE GIS ANALISYS AS AN APROACH TO HUMAN DECISION MAKING}

\author{
ABSTRACT \\ La Primavera (Santa Cruz province, Argentina) archaeological locality was occupied by mobile \\ * CONICET, Facultad de Ciencias Naturales y Museo - UNLP, División de Arqueología, Museo de La Plata, Paseo del Bosque s/n, \\ lmagnin@fcnym.unlp.edu.ar.
}


hunter-gatherers from early to late Holocene (ca. 9500-940 BP). In previous studies, the distributions of archaeological evidences at this locality were analyzed using Geographic Information Systems (SIG) to detect recurrences in the use of space. Among the different evidence classes analyzed, the rock art distribution is conditioned by the presence of naturally available rock surfaces, and these are determined in turn by local geomorphology. Therefore, to study human decisions and art production in the context of the landscape, it is necessary to consider the distribution of naturally available rock surfaces. To address this problem, in this article locations of caves with rock art are compared with locations of caves without art which present rock surfaces adequate for painting and present good preservation conditions.

The results obtained do not reach a statistical significance, but allow us to formulate the following working hypotheses: the caves chosen to perform paintings where those located closer to resources as water sources, lithic quarries, ochre pigments sources, closer to mobility pathways and which present wider viewsheds.

KEY WORDS: rock art, GIS, hunter-gatherers, Argentinean Patagonia.

\section{INTRODUCCIÓN}

En este trabajo se busca investigar la producción de arte rupestre en la localidad La Primavera desde una perspectiva espacial a escala del paisaje, partiendo de la pregunta ¿por qué las sociedades cazadoras recolectoras decidieron pintar en ciertas cuevas y aleros y no en otros con similares condiciones en cuanto a la presencia de paredes aptas para ser usadas como soportes? Para abordar este tema se considera aquí que el arte rupestre no es realizado por decisiones arbitrarias e individuales, sino que el impulso de realizar imágenes, los motivos elegidos y la localización son resultado de procesos de decisión guiados por sistemas de valores consensuados (Lenssen-Erz 2004).

La localidad arqueológica La Primavera se encuentra entre los $47^{\circ} 48^{\prime} 17.724^{\prime \prime}$ y $47^{\circ} 54^{\prime}$ $8.073^{\prime \prime}$ de latitud sur y los $69^{\circ} 1$ ' $17.2^{\prime \prime}$ y $68^{\circ} 53^{\prime}$ $14.538^{\prime \prime}$ de longitud oeste, al norte del macizo Central del Deseado, provincia de Santa Cruz, Argentina (Fig. 1). El estudio arqueológico de esta localidad comenzó en el año 2003, motivado por la exploración de las cabeceras de las cuencas de drenaje de los zanjones Blanco y Rojo, en cuya desembocadura se hallaron importantes evidencias para comprender el problema del poblamiento de América en el sitio Piedra Museo (Miotti et al. 1999). Las investigaciones se orientaron primero a la realización de excavaciones estratigráficas que permitieron determinar que el sector fue ocupado por grupos cazadores recolectores entre los $9.518 \pm 64$ años AP (AA65175, fechado realizado sobre carbón de una estructura de fogón en Cueva Maripe) (Miotti et al. 2007) y los $939 \pm 59$ años AP (AA85460, realizado sobre hueso de Lama guanicoe recuperada en el sitio a cielo abierto La Quinta) (Magnin 2010).

Luego, con el fin de estudiar las formas en que estas poblaciones móviles usaron el paisaje local, se comenzó a desarrollar un análisis espacial aplicado a las distribuciones de evidencia arqueológica hallada sobre la superficie del terreno (Magnin 2010). Para ello se desarrolló un programa de prospección para el registro de las distribuciones espaciales de sitios, concentraciones y hallazgos aislados (sensu Borrero et al. 1992). Al incluir la diversidad de formas en que se presenta el registro arqueológico, más allá del estudio de sitios arqueológicos, se buscó obtener información complementaria a la proveniente de esos loci representativos de actividades que produjeron muchos desechos o que fueron reutilizados recurrentemente. De este modo se logró generar una imagen más completa de la manera en que las sociedades del pasado usaban diferencialmente el espacio (Foley 1981, Gamble 1990, Allen 1991, Borrero et. al. 1992, Borreo 1995, Belardi \& Borrero 1999, Magnin 2008). Por tratarse de hallazgos en superficie, se asume que los patrones observados son resultado de la historia de los asentamientos, y para su interpretación se incluyen estudios geoarqueológicos que permiten evaluar procesos que actuaron y actúan hoy afectando la visibilidad y preservación diferencial de los conjuntos (Borrero 2001, Borrazo 2004, Foley 1981, Butzer 1989, Favier 2001, Rossignol 
\& Wandsnider 1992, Sivertsen 1980, Waters 1992 , Waters \& Kuehn 1996, entre otros). Teniendo en cuenta estos procesos naturales de formación, $y$ considerando al registro arqueológico de superficie como una muestra promediada (Franco \& Borrero 1996:343), las tendencias halladas permiten abordar las conductas recurrentes en el uso del paisaje a través del tiempo.

La metodología aplicada es un análisis locacional mediante Sistemas de Información Geográfica (SIG). Los modelos locacionales buscan modelar la relación entre los grupos humanos, sus actividades y el medioambiente (Judge \& Sebastian 1988). Si bien este tipo de análisis puede desarrollarse con fines predictivos (Wheatley \& Gillings 2002), en este caso el interés se centra en detectar patrones y cuantificarlos (Woodman \& Woodward 2002) para luego generar explicaciones posibles para el uso del paisaje en la localidad (van Leusen 1996). Sumado a esto, aquí se considera que la identificación de relaciones entre factores no explica las distribuciones arqueológicas en términos causales (Wescott 2000), en cambio el hallazgo de patrones lleva a generar nuevas hipótesis y buscar una interpretación apoyada en las demás líneas de evidencia (Magnin 2009, Woodman \& Woodward 2002).

El presente trabajo es un avance respecto al estudio de la localización del arte rupestre y una continuación del análisis que fue planteado antes para distintas clases de evidencias de superficie (Magnin 2010). Busca generar datos formales para describir su emplazamiento y realizar una propuesta metodológica para abordar el problema del condicionamiento que ejerce la distribución natural de soportes aptos para ser pintados en la región. El abordaje de este problema permitirá generar información para avanzar en el estudio de las decisiones de realización de arte rupestre a escala del paisaje.

\section{Geografía de la localidad}

El relieve de este sector se caracteriza por la presencia de serranías y planicies con una pendiente regional suave hacia el este. El terreno presenta elevaciones entre los 400 y los 900 msnm y su sistema fluvial está parcialmente integrado ya que gran parte del mismo es un sistema endorreico múltiple. Está formado por cursos de régimen efímero que llevan agua de las precipitaciones pluviales y del derretimiento de la nieve estacional, durante el invierno y comienzo de la primavera (Minería 2012). Los afluentes principales de la localidad son los que corren por el cañadón de La Primavera, el Zanjón de Aquilino y el Zanjón de la Mora (Fig.1). Los tres son tributarios de un afluente de mayor jerarquía que fluye por el Zanjón Blanco. Las fuentes de agua permanente en la localidad se presentan localizados en las periferias de coladas de rocas basálticas, las cuales funcionan como reservorio del agua de lluvia que percola a través de la roca y sale por sectores puntuales en forma de vertientes o aguadas (Mazzoni 2007). Las formaciones rocosas principales tienen origen volcánico, constituyen las elevaciones máximas y se encuentran cubiertas por mantos basálticos que las protegen de la erosión. Chön Aike, una de las formaciones más importantes, es parte del Grupo Bahía Laura de edad Jurásica y está constituida principalmente por ignimbritas riolíticas que se disponen en mantos compactos y espesos formando grandes paredones y crestas muy abruptas. Estas rocas forman asomos redondeados en los que no se observan planos de estratificación y pueden tener disyunción columnar en su parte superior (Panza 2001). En ellas típicamente se da la formación de grandes cavernas y oquedades por meteorización y acción eólica (Panza 2001). Algunas de esas cuevas y aleros presentan pinturas rupestres y otras evidencias arqueológicas en superficie y en estratigrafía, indicando que fueron usadas por cazadores recolectores en momentos pre-hispánicos (Miotti et al. 2007).

\section{El paisaje en estudios regionales de arte rupestre}

El estudio del arte rupestre en relación con el paisaje no es exclusivo de los análisis locacionales como el que se propone aquí. Desde perspectivas teóricas tanto idealistas como materialistas (Carden 2009, Fiore \& Hernández Llosas 2007) se ha considerado la relación del arte con el paisaje. Desde la arqueología normativa, el arte rupestre se entendió como una forma simbólica de expresar ideas y vivencias de carácter mágico-religioso, que dejaron su impronta sobre el entorno natural (Gradin 1989, Schobinger 1956, Schobinger \& Gradin 1985). En el caso de los estudios realizados por Schobinger (1956) en el norte de Neuquén, el estudio de la localización del arte en el paisaje incluyó su relación con distintas geoformas, su altitud relativa en el paisaje, el dominio 


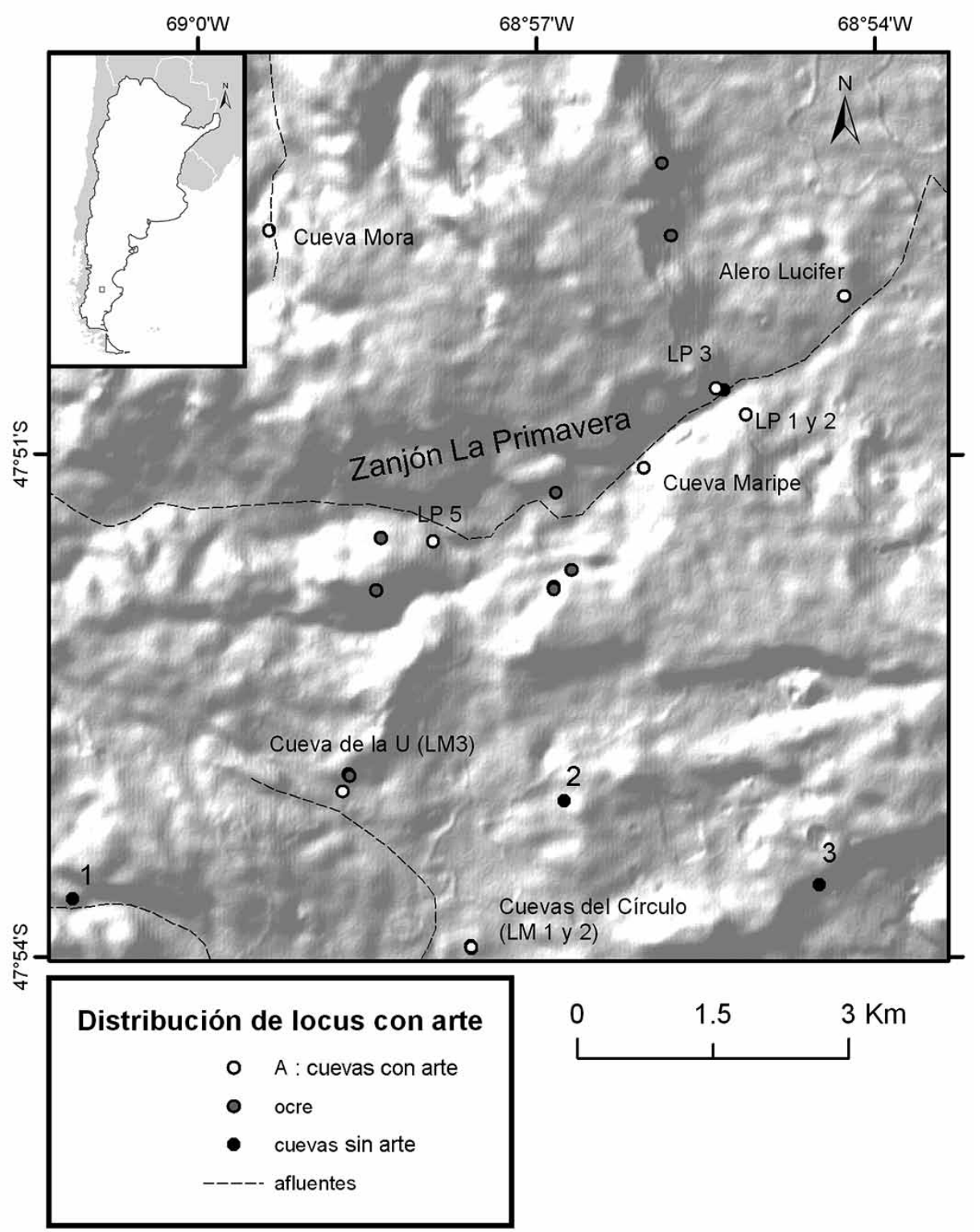

Fig. 1. Distribución de cuevas con y sin arte rupestre en el sector prospectado. Cuevas sin arte: 1) Cueva del Valle Escondido; 2) Cueva del Lagarto; 3) Cueva de la Subida.

visual desde su emplazamiento y su relación con rutas de movilidad diaria. Con respecto a los motivos en la elección de estos lugares, se vincularían a cuestiones profundamente asociadas con su dimensión espiritual. También Gradin (1989) en el caso de los grabados rupestres del Cerro Yanquenao en Chubut, estudió las relaciones espaciales y de intervisibilidad entre los grabados y un enterratorio cercano y usando información mitológica de los grupos tehuelches y mapuches provenientes de la región propuso motivaciones simbólicas para sus emplazamientos.

Desde los estudios procesuales y sistémicos se consideró al arte como un artefacto, en cuanto a su función como signos y representaciones que son portadores de información que circula dentro de los sistemas de asentamiento y movilidad de los grupos cazadores-recolectores (Aschero 1988, 1997). Dentro de esta perspectiva el arte forma parte de 
sistemas de comunicación visual, que presentan un valor adaptativo al brindar información acerca de la movilidad y la identidad de sus productores anclada en el espacio (Aschero 1996, 1997). Por ejemplo, en el noroeste de la Provincia de Santa Cruz, Aschero (1996) estudió las semejanzas formales entre motivos, el emplazamiento geográfico del arte y la distribución de recursos naturales en relación con otras evidencias arqueológicas. El autor encontró que los motivos animalísticos se localizan en localidades de asentamiento con alta redundancia ocupacional, y con evidencias de actividades múltiples. Esta redundancia en las ocupaciones se habría dado porque eran zonas de alta abundancia de recursos de caza y combustibles, donde había complejos de sitios que incluían algún sitio de mayor extensión relativa que proveía de reparo para un número grande de individuos. En cambio las manos negativas ocurren indistintamente en lugares con fuerte redundancia de ocupación o en aleros pequeños usados más esporádicamente, localizados en sectores de tránsito entre áreas de abundancia de recursos y evidencias de asentamiento. Estas recurrencias le permitieron al autor reconocer localidades de asentamiento y áreas de tránsito entre ellas y reconstruir los circuitos de movilidad y los territorios de los cazadores-recolectores a partir del estudio del arte rupestre.

Otros ejemplos de análisis de arte rupestre en el paisaje lo constituyen los estudios realizados hacia el centro oeste de Santa Cruz (Belardi et al. 2010, Belardi \& Goñi 2006, Goñi et al. 2007, Re \& Guichón 2010, entre otros). La distribución de recursos, el emplazamiento del arte rupestre en distintas geoformas y la accesibilidad natural del sector de mesetas en el que se emplazan miles de representaciones rupestres grabadas, son argumentos que se tomaron para analizar la dinámica estacional de las poblaciones cazadoras recolectoras en el Holoceno tardío. La alta frecuencia y gran diversidad de motivos rupestres grabados registrados en la meseta del lago Strobel, similares a los representados en regiones adyacentes (como la costa noreste del lago Viedma, la meseta del Cardiel Chico y la meseta de San Adolfo), la condición óptima de ese espacio con respecto a la disponibilidad permanente de agua y su posición central con respecto a rutas de menor coste entre las regiones adyacentes mencionadas, permitió a los autores plantear eventos de convergencia poblacional en este sector durante las estaciones de primavera y verano.

El estudio del arte en el paisaje también se realizó desde una posición intermedia entre el materialismo y el idealismo (Ingold 1993). El concepto de la temporalidad del paisaje plantea que el mismo no es homologable a la naturaleza como un objeto externo a la percepción humana, ni es opuesto a la naturaleza como percepción humana, ya que los seres humanos integran el paisaje mediante sus acciones y movimientos, y a la vez el paisaje adquiere historicidad por el significado de dichas acciones (Criado 1999; Ingold 1993; Tilley 1994). En el caso de los sitios con grabados rupestres en las localidades Piedra Museo y Aguada del Cuero, al norte del macizo Central de Santa Cruz, Carden $(2009,2010)$ estudió la estructura interna de los motivos representados, sus relaciones con otros motivos, sus condiciones de visibilidad y sus emplazamientos. A partir de estos estudios concluyó que los motivos rupestres pudieron haber marcado los territorios de los grupos cazadores-recolectores a partir de una señalización de lugares y caminos que tuvieron connotaciones sagradas. La ritualidad del paisaje habría estado evidenciada en el formalismo, el tradicionalismo y el simbolismo de las imágenes y su espacialidad.

Como es evidente a partir de los trabajos citados, más allá de las interpretaciones derivadas de distintos enfoques teóricos y limitadas por las diferentes escalas de análisis (Hyder 2004), las propuestas de estudio presentadas tienen en común la inclusión del arte rupestre en el contexto del paisaje, caracterizando su emplazamiento mediante indicadores tales como su localización geográfica, la presencia de abrigo, la asociación con vías de movilidad, asociación con distintos recursos de subsistencia y distintos aspectos referentes a la visibilidad de y desde los lugares de emplazamiento del arte. Estos son factores que también han sido recurrentemente analizados en estudios de arte rupestre en otras regiones (por ejemplo ver Arsenault 2004, Bradley et al. 1994, Hyder 2004, Lensenn-Erz 2004, Martínez 2006, Ross et al. 2008).

Desde el punto de vista metodológico, la aplicación de SIG ha demostrado ser una importante herramienta de investigación en el estudio del paisaje y el arte rupestre incluso desde perspectivas teóricas muy diferentes. Además, se han modelado mediante SIG factores que no se restringen a aspectos de la materialidad física, sino que buscan incluir las 
dimensiones sociales y también simbólicas (por ejemplo ver Gaffney et al. 1996, Llobera 1996), formalizando la presentación de los datos y facilitando la comparación de resultados entre distintos estudios y la replicación de distintos análisis (Magnin 2009). Estudios locacionales en La Primavera

Durante el trabajo de campo desarrollado en el año 2008 se realizaron transectas paralelas con orientación norte-sur, separadas cada $1 \mathrm{~km} \mathrm{y}$ abarcando sistemáticamente toda la localidad con el fin de registrar la diversidad y distribución de evidencias arqueológicas y las características del ambiente. El estudio de los distintos tipos de materiales preservados en superficie, principalmente artefactos líticos, sumado a una evaluación de la condición de visibilidad arqueológica en cada caso particular permitió distinguir diez clases de evidencia: apostadero de caza, cantera, campo de caza, campamento transitorio, locus de actividades limitadas, locus de actividades múltiples, taller, locus de talla ocasional, estructuras de piedra interpretables como posibles enterratorios y locus con arte. Como parte del procedimiento metodológico también se registraron locus de evidencia negativa (Magnin 2010). En cuanto a las características ambientales, se registraron los recursos naturales, como las aguadas que constituyen fuentes permanentes de agua en esta región, otras fuentes temporarias como los afluentes efímeros, que solo presentan agua luego de las precipitaciones y las fuentes de aprovisionamiento de rocas. Posteriormente se usaron técnicas de SIG para definir la unidad geomorfológica en que se emplaza y el grado de reparo del viento que presenta cada emplazamiento, determinar distancias de coste hasta los recursos antes mencionados, trazar redes de circulación (caminos óptimos) y calcular la amplitud de las cuencas visuales desde cada lugar donde la evidencia arqueológica fue hallada. Todos estos fueron considerados factores que pudieron ser de interés para definir los lugares donde los cazadores-recolectores habrían desarrollado actividades de diverso tipo (estas también fueron tomadas en otras investigaciones sobre arqueología de cazadores recolectores, por ejemplo Krist 2006, Kvamme 1988, Ridges 2006). De este modo, se estudió la distribución de cada clase de evidencia arqueológica como factor dependiente, y la distancia

Tabla 1. Arte rupestre en cuevas y aleros en el sector prospectado. (*) Las dimensiones de las cuevas se indican en metros de ancho en la entrada $\mathrm{x}$ metros de profundidad; las dimensiones de aleros se indican en metros de longitud del mismo. Citas: 1) Carden 2009 ; 2) Magnin 2006, 3) Magnin 2008.

\begin{tabular}{|c|c|c|c|}
\hline Sitio & Dimensiones* & Motivos pintados & Cita \\
\hline Cueva Maripe & $26 \times 24 \mathrm{~m}$ & $\begin{array}{l}\text { Manos de adultos y de niños, zoomorfos y motivos geométricos. } \\
\text { Uso de color rojo, rosa, blanco, amarillo y violáceo. }\end{array}$ & 1 \\
\hline La Primavera 1 & $4 \times 6 \mathrm{~m}$ & Manos negativas de color rojo y blanco, zoomorfo rojo & 1 \\
\hline La Primavera 2 & $8 \times 12 \mathrm{~m}$ & $\begin{array}{l}\text { Manos negativas naranjas (algunas de niños) asociadas a manchas, } \\
\text { pisada de felino blanca y manchas rojas }\end{array}$ & 1 \\
\hline La Primavera 3 & $3 \times 10 \mathrm{~m}$ & Manos negativas de color rojo y blanco & 1 \\
\hline La Primavera 5 & $3 \times 10 \mathrm{~m}$ & $\begin{array}{l}\text { Manos negativas rojas, negras y blancas (la mitad son de niños), } \\
\text { figura geométrica compleja polícroma en los mismos colores }\end{array}$ & 1 \\
\hline Alero Lucifer & $12 \mathrm{~m}$ de longitud & Manos negativas de color rojo & 1,2 \\
\hline Cueva Mora & $\begin{array}{l}\text { Cámara norte } 6 \text { × 3m, } \\
\text { cámara sur } 3 \times 3.50 \mathrm{~m}\end{array}$ & Círculos, manchas y líneas de color naranja & 3 \\
\hline Cueva de la U & $\begin{array}{l}\text { Complejo de aleros y } \\
\text { cueva que se extienden } \\
\text { por } 120 \mathrm{~m}\end{array}$ & Manos negativas de color rojo y negro & 1,2 \\
\hline $\begin{array}{c}\text { Cueva } \\
\text { del Círculo } 2\end{array}$ & $6 \mathrm{~m}$ de longitud & Negativos de manos de color rojo & 1,2 \\
\hline $\begin{array}{c}\text { Cueva } \\
\text { del Círculo } 3\end{array}$ & $6 \times 12 \mathrm{~m}$ & Manos negativas y círculo de puntos de color naranja & 1,2 \\
\hline
\end{tabular}



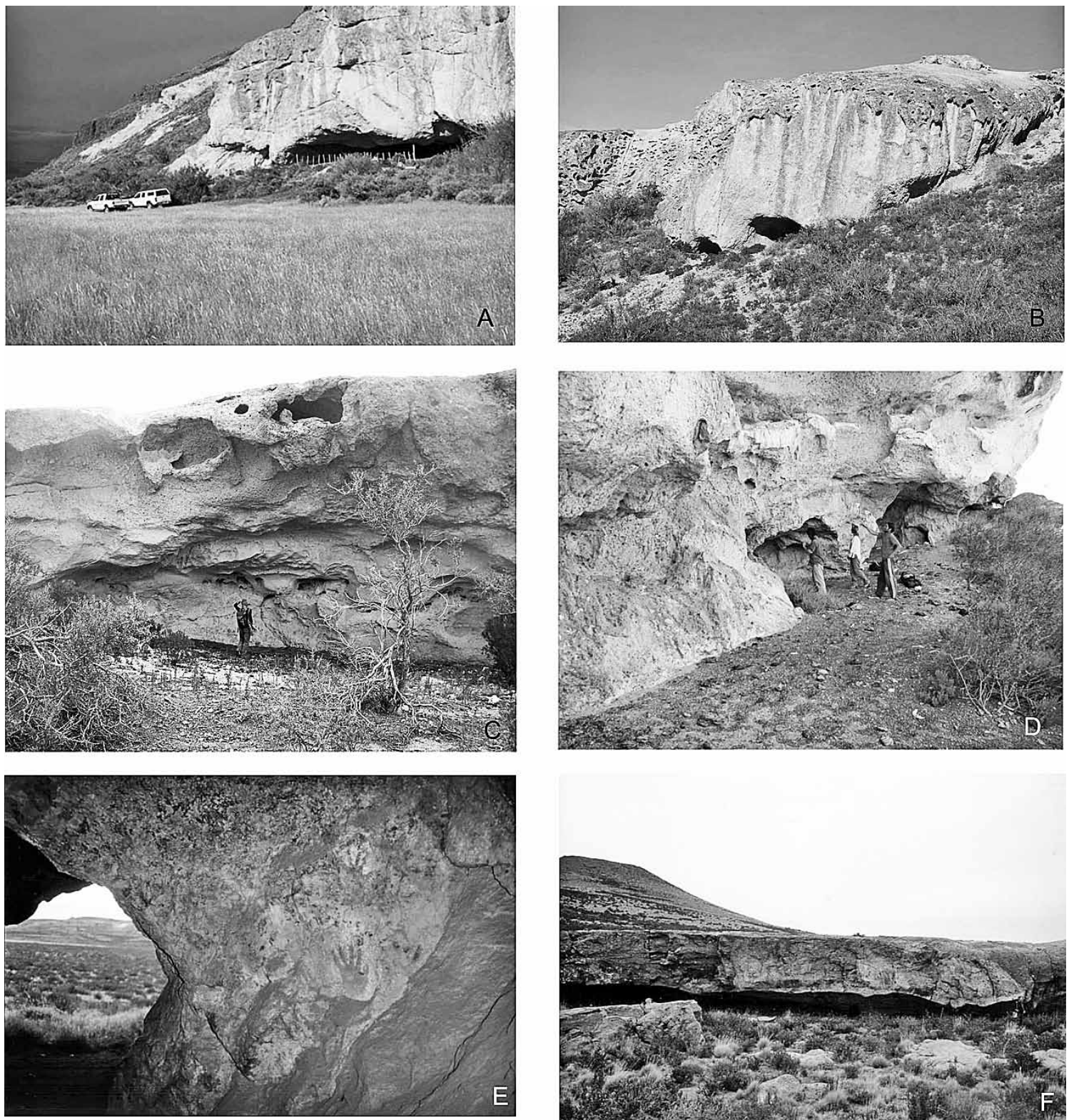

Fig. 2. Algunas de las cuevas con pinturas rupestres dentro del sector prospectado. a) Cueva Maripe, en el cañadón de La Primavera; b) Aleros La Primavera 1 y 2; c) Alero Lucifer; d) Cueva Mora; e) Motivos de manos negativas sobre una pared oscura de la Cueva del Círculo 3; f) Cueva de la U.

a recursos, presencia de reparo, distancia a las vías de movilidad y la amplitud de cuencas visuales como factores independientes del análisis o variables locacionales (para una discusión general ver Kvamme 2006). El protocolo permitió definir patrones que luego condujeron a ensayar explicaciones para entender sus localizaciones (Magnin 2010).

Estos trabajos previos permitieron advertir que en el caso de los loci con arte rupestre el análisis de su localización en el paisaje se ve afectado por la distribución natural de cuevas y abrigos rocosos. En estos lugares se presentan los soportes aptos para pintar y además existen condiciones de protección que permiten la preservación de pinturas rupestres. El modelar la localización de sitios con arte rupestre como se realizó con otras clases de evidencia sin tener en cuenta esto 

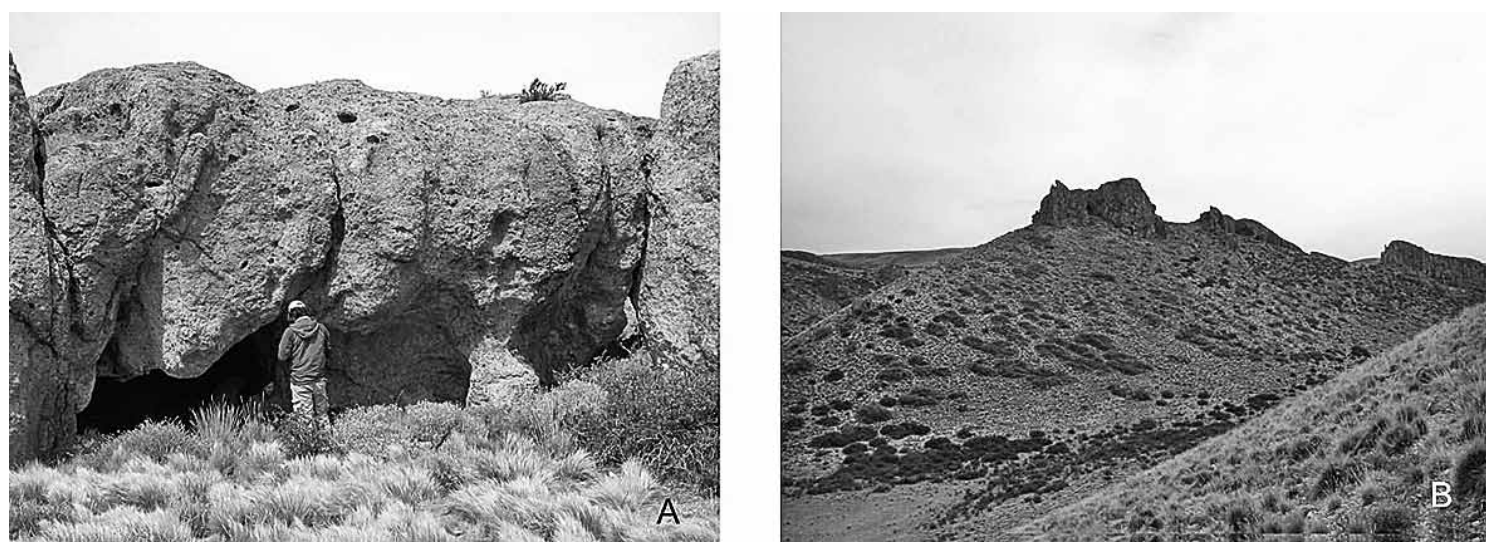

Fig. 3. Cuevas sin arte, a) Cueva del Valle Escondido y b) Cueva del Lagarto.

último, no daría información acerca de las decisiones humanas de uso del paisaje. Por el contrario, indicaría la localización de las cuevas y abrigos reflejando las distribuciones de variables geológicas como el tipo de rocas, la acción de procesos hidrológicos, la forma del terreno y otros factores (Kvamme 2006). Esto llevó a plantear un tratamiento metodológico especial, y el presente trabajo es un avance en ese sentido. Lo que se propone es realizar una comparación de dos muestras: una constituida por cuevas y aleros con arte rupestre y otra formada por cuevas y aleros que, a pesar de presentar soportes aptos para pintar y tener condiciones de preservación similares, no cuentan con motivos rupestres pintados (Tabla 1 y Fig. 2). Al analizar las distribuciones de cuevas con y sin arte en relación a los factores ambientales mencionados sería posible descartar el efecto que tuvo la distribución natural de soportes en el paisaje para avanzar en el estudio de las decisiones humanas respecto de esta actividad. Lo que se espera encontrar son diferencias de las dos muestras respecto a los factores considerados, que permitan generar hipótesis acerca de los posibles motivos para las elecciones realizadas.

\section{Cuevas y aleros analizados}

Se registraron en total ocho cuevas y aleros con arte de la localidad. Estos son: Cueva Maripe, los abrigos La Primavera 1y2, La Primavera 3, La Primavera 5, Alero Lucifer, Cueva Mora, Cueva de la U y Cuevas del Círculo 2 y 3 (Tabla 1 y Fig. 2). Estas presentan motivos figurativos como los negativos de manos, zoomorfos y pisadas, y abstractos como manchas, líneas, puntos, círculos, y motivos geométricos complejos. Los colores de las pinturas son diversos: rojo, naranja, rosado, blanco, amarillo, negro y violáceo (Carden 2009).

Con respecto a las cuevas sin arte registradas en la localidad, tres de ellas presentaron soportes con condiciones de homogeneidad y extensión suficiente como para ser pintadas. Estas son: la Cueva del Valle Escondido, la Cueva del Lagarto y la Cueva de la Subida (las dos primeras pueden verse en la Fig. 3).

\section{METODOLOGÍA}

La metodología consiste en analizar la distribución de la evidencia arqueológica y la muestra control (cuevas y aleros sin arte) en relación a un número de factores locacionales con la finalidad de detectar sus posibles patrones de emplazamiento. El uso de muestras control ha sido destacado como una aproximación con potencial en el estudio de arte rupestre (por ejemplo Bradley et al. 1994; Scheinsohn et al. 2011, ver también el uso de registros de ausencia de arte en intervalos fijos a lo largo de los soportes rocosos en Fiore \& Ocampo 2009) ya que permite caracterizar las situaciones donde las pinturas rupestres están presentes y donde no lo están a pesar de haber soportes rocosos adecuados. Como ya se mencionó, este procedimiento sirve para hallar tendencias respecto a las variables que pudieron incidir en la elección de espacios para la realización de arte.

Los factores analizados fueron seleccionados según criterios teóricos, y técnicos (Magnin 2010, 2011). Por un lado se seleccionaron factores que 
pudieron ser importantes para tomar decisiones dentro de las sociedades estudiadas (ver Ebert 2000, Krist 2006). Por otro lado, se evaluó que estos factores puedan ser modelados mediante datos adecuados para ingresar al SIG, que estos datos fueran apropiados referentes actualísticos del paisaje del pasado (Kvamme 2006), y que presenten un error que pueda ser evaluado (Bosque \& Gómez 2007, Veregin 1997). Estas son: distancias de coste a fuentes de agua permanentes y temporarias, a canteras de aprovisionamiento líticas, a fuentes de ocre, y a caminos (vías de acceso modeladas entre locus de actividades múltiples); amplitud de las cuencas visuales; topografía en que se emplaza y presencia de reparo. El tratamiento metodológico seguido para el modelado de cada variable es el mismo aplicado en Magnin (2010, 2011) y se describe brevemente a continuación.

\section{Análisis SIG}

Se usó el software ArcGis Desktop (Esri 2010) conformando un SIG que incluye la siguiente información georeferenciada:

a) Una cobertura vectorial de polígonos representando distintas unidades topográficas. Las unidades de topografía abrupta comprenden aquellos sectores del terreno que presentan más de $15^{\circ}$ de declive; mientras que la topografía suave-baja representa sectores de menor declive localizados en fondos de valles y cuencas.

b) Una cobertura raster que modela la calidad del reparo existente, clasificando el territorio en sectores abrigados y expuestos. Para generar el modelo se usaron registros GPS combinados con un mapa de orientaciones del terreno reclasificado en relación con la dirección de los vientos predominantes.

c) Coberturas raster binarias que representan la amplitud de las cuencas visuales desde cada cueva.

d) Coberturas raster que representan distancias de coste acumulado calculadas en base a una superficie de fricción (Conolly \& Lake 2006, van Leusen 2002) generada mediante el algoritmo descripto en Tobler (1993) y adaptado como es usado en Fábrega $\&$ Parcero (2007). Sus celdas presentan valores de distancia medida en minutos de marcha a:

1) Fuentes permanentes de agua, que son aguadas registradas mediante GPS y otras detectadas por análisis de imágenes satelitales (Gómez \& Magnin
2006);

2) Fuentes permanentes sumadas a fuentes temporarias de agua, como afluentes y lagunas temporarias digitalizadas a partir de aerofotografías;

3) Canteras de aprovisionamiento líticas registradas en prospecciones;

4) Fuentes de ocres registradas en prospecciones;

5) Red de caminos principales;

6) Red de caminos secundarios.

Las redes de caminos principales y secundarios fueron modeladas entre loci de actividades múltiples según la metodología modificada de Fábrega \& Parcero (2007). Estos caminos son construcciones hipotéticas. La metodología para su trazado implicó usar como puntos de origen y destino para el trazado de caminos de menor coste los loci de actividades múltiples conocidos. Estos fueron tomados como una muestra de la totalidad de lugares que debieron haberse usado como campamentos base residenciales a lo largo de la historia de ocupación de esta localidad. Se asume que estos sitios no fueron ocupados sincrónicamente, sino que estas líneas de movilidad unieron los paraderos que a través del tiempo fueron ocupados y reocupados por los grupos humanos en sus traslados desde y hacia distintos extremos del territorio regional (ver Magnin 2010).

Todas estas coberturas se superpusieron mediante SIG con una cobertura vectorial de puntos que representan la localización de las cuevas con arte y las cuevas sin arte tomadas en el campo con GPS no diferencial. Los valores de cada variable analizada fueron adjudicados a las cuevas con y sin arte mediante consultas puntuales de intersección.

\section{RESULTADOS}

Los conjuntos de cuevas con y sin arte evaluados no difieren en cuanto a la topografía en que se ubican, ya que la mayoría de los casos $(62,5 \%$ de cuevas con arte y $66,7 \%$ de cuevas sin arte) se emplaza en sectores de pendientes abruptas. Del mismo modo, respecto al factor que modela la presencia de reparo, la mayoría de las cuevas con arte $(62,5 \%)$ y el total de las cuevas sin arte se localizan en lugares sin reparo, expuestos al viento.

Respecto a las cuencas visuales, las cuevas analizadas se localizan en sectores desde los que puede verse entre el 1 y el $11 \%$ de una cuenca total teórica, siendo las cuevas con arte las que presentan 
los mayores valores de visibilidad.

En cuanto a las distancias a los recursos, en la tabla 2 y en las figura 4 pueden verse que las cuevas que presentan pinturas rupestres son las que tienden a localizarse a distancias menores a los recursos y las redes de caminos modeladas.

Las distribuciones de valores obtenidos para la amplitud de cuencas visuales y las distancias a recursos entre cuevas con y sin arte fueron sometidas a la prueba de Kolmogorov-Smirnov, siendo la hipótesis nula que las dos muestras comparadas no son diferentes (Tabla 3). Como las muestras son muy pequeñas (m y $n<25)$, se realizó la consulta de los valores críticos para la región de rechazo unidireccional de los valores obtenidos (D 8,3) en la tabla de Siegel \& Castleman (1999:386), lo que determinó la ausencia de diferencias significativas entre las muestras (ver Tabla 3).

\section{DISCUSIÓN}

Teniendo en cuenta los procesos geomorfológicos de la localidad (Panza 2001), la similar distribución de las cuevas con y sin arte respecto a las variables topografía y condición de reparo, estaría reflejando que las cuevas se formaron en sectores de topografía abrupta y que se presentan expuestos a la acción eólica constante desde el cuadrante oeste. Por lo tanto su emplazamiento está determinado por el proceso natural de formación cuevas en esta localidad, lo que implica que estas variables no permiten obtener información acerca de las decisiones humanas en este caso de estudio.

Continuando con los demás factores analizados, las amplitudes de cuencas visuales y las distancias entre recursos y cuevas con y sin

Tabla 2. Valores de los factores explorados borrar para cuevas con y sin arte. La calidad de reparo se indica mediante A si se trata de unidades de terreno abrigadas, reparadas del viento o E si se presentan expuestas; las distancias se expresan en minutos de marcha.

\begin{tabular}{|c|c|c|c|c|c|c|c|c|c|}
\hline 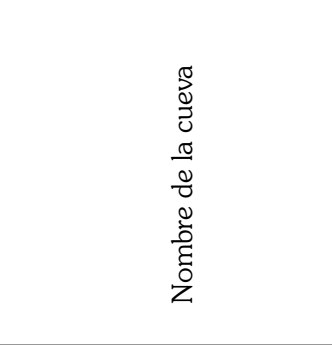 & 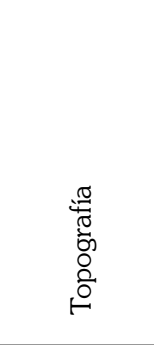 & 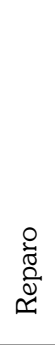 & 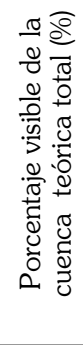 & 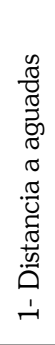 & 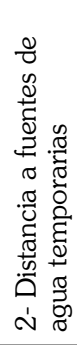 & 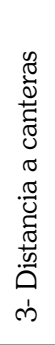 & 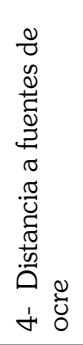 & 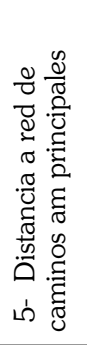 & 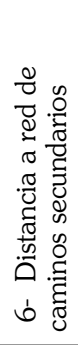 \\
\hline Cueva Mora & abrupta & $E$ & 3 & 10 & 3 & 57 & 86 & 40 & 44 \\
\hline Cueva Maripe & abrupta & A & 1 & 6 & 2 & 7 & 18 & 1 & 1 \\
\hline Cueva de la U & suave_baja & $\mathrm{E}$ & 2 & 5 & 5 & 17 & 5 & 0 & 3 \\
\hline Circulo & suave_baja & $\mathrm{E}$ & 5 & 2 & 2 & 24 & 38 & 9 & 11 \\
\hline Alero Lucifer & suave_baja & $E$ & 8 & 16 & 4 & 15 & 33 & 5 & 2 \\
\hline La Primavera 1 y 2 & abrupta & $\mathrm{A}$ & 11 & 15 & 10 & 34 & 46 & 9 & 1 \\
\hline La Primavera 3 & abrupta & $E$ & 6 & 9 & 5 & 29 & 41 & 6 & 10 \\
\hline La Primavera 5 & abrupta & $\mathrm{A}$ & 1 & 8 & 1 & 40 & 136 & 4 & 7 \\
\hline $\begin{array}{l}\text { Valores de la mediana en } \\
\text { cuevas con arte }\end{array}$ & & & 7 & 8 & 4 & 24 & 38 & 5 & 3 \\
\hline Cueva del Valle escondido & abrupta & $\mathrm{E}$ & 1 & 4 & 3 & 53 & 73 & 39 & 37 \\
\hline Cueva del Lagarto & suave_baja & $\mathrm{E}$ & 5 & 18 & 18 & 11 & 39 & 5 & 17 \\
\hline Alero de la subida & abrupta & $\mathrm{E}$ & 3 & 10 & 10 & 54 & 87 & 14 & 9 \\
\hline $\begin{array}{l}\text { Valores de la mediana en } \\
\text { cuevas sin arte }\end{array}$ & & & 4 & 10 & 10 & 53 & 73 & 14 & 17 \\
\hline
\end{tabular}




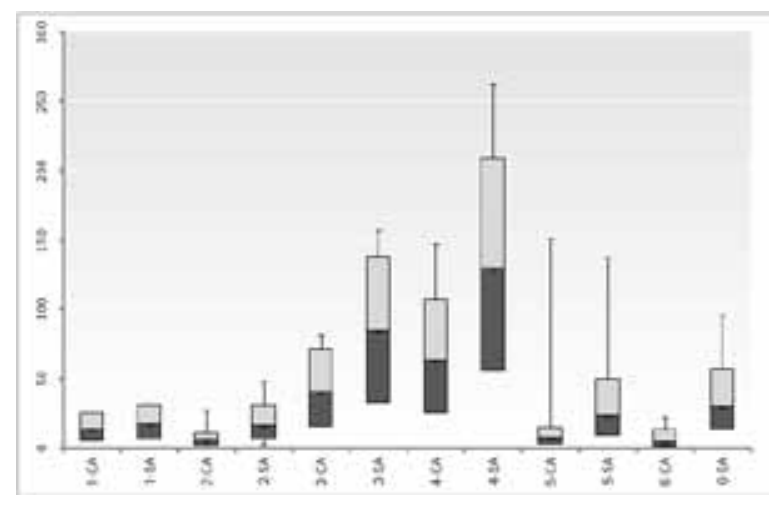

Fig. 4. Gráfico de caja mostrando las distancias (medidas en minutos de marcha) desde cuevas con arte (CA) y sin arte (SA) a 1) las fuentes permanentes de agua, 2) fuentes permanentes $y$ temporarias de agua, 3) canteras, 4) fuentes de ocre, 5) caminos principales y 6) caminos secundarios.

arte tampoco presentaron diferencias desde el punto de vista de la significación estadística. Esto podría estaría indicando que los recursos están muy homogéneamente distribuidos en el espacio, o bien que para decidir dónde realizar arte rupestre se tomaron en cuenta otros factores, distintos a los aquí analizados. Sin embargo, debemos tener en cuenta que la falta de diferencias significativas también puede deberse al tamaño pequeño de las muestras comparadas (ver Siegel \& Castellman 1995). Los resultados obtenidos, sin embargo, sugieren la existencia de algunas tendencias que permiten plantear como hipótesis para seguir trabajando que las cuevas elegidas para realizar pinturas serían aquellas más cercanas a recursos como las aguadas y afluentes

Tabla 3. Filas: Valores D y p de la prueba KolmogorovSmirnov para dos muestras de $\mathrm{m}=8, \mathrm{n}=3$ y alfa $=0,05$. Para los valores de $\mathrm{mnDm}, \mathrm{n}$ calculados el valor crítico es $\mathrm{c} 0,05=19$

(Siegel y Castellman 1995:386) indicando que no se puede

rechazar la hipótesis nula según la cual las muestras no son diferentes. Columnas: Variables analizadas: distancias a 1) fuentes permanentes de agua, 2) fuentes permanentes y temporarias de agua, 3) canteras de aprovisionamiento lítico, 4) fuentes de ocre, 5) caminos principales y 6) caminos secundarios; y 7) amplitud de cuencas visuales

\begin{tabular}{|l|c|c|c|c|c|c|c|}
\cline { 2 - 9 } \multicolumn{1}{c|}{} & \multicolumn{7}{c|}{ Factor } \\
\hline & 1 & 2 & 3 & 4 & 5 & 6 & 7 \\
\hline $\mathrm{D}$ & 0,333 & 0,542 & 0,542 & 0,5 & 0,542 & 0,625 & 0,375 \\
\hline valor-p & 0,913 & 0,38 & 0,38 & 0,482 & 0,38 & 0,221 & 0,823 \\
\hline $\mathrm{mnD}_{\mathrm{m}, \mathrm{n}}$ & 7,992 & 13,008 & 13,008 & 12 & 13,008 & 15 & 9 \\
\hline
\end{tabular}

temporarios, las fuentes de aprovisionamiento de rocas útiles para la talla y las fuentes de ocre útil para confección de pinturas; que los espacios escogidos se encontrarían más cerca de las vías de movilidad del paisaje y que presentarían cuencas visuales más amplias que las cuevas que no fueron elegidas para realizar arte. Una manera de continuar estudiando estas tendencias es mediante la incorporación de nuevos datos. Por ejemplo, se podría ampliar la escala espacial de la investigación para incorporar otros sitios con arte localizados en sectores aledaños. Los sitios con pinturas más cercanos conocidos hasta el momento se encuentran en el sector de Los Ventisqueros (1 km al oeste del área de estudio), la Localidad Las Mercedes y el cañadón de la Víbora (localizados a 2,5 y 6,7 km al sur, respectivamente). Sin embargo, para poder incluirlos también haría falta ampliar el registro de los factores ambientales de interés que se ingresaron al análisis a partir de datos de campo (canteras, ocre y aguadas), y esto requiere de nuevas prospecciones sistemáticas. De hecho, la localización de las cuevas sin arte (especialmente la cueva del Valle escondido y de La Subida) en puntos cercanos a los límites del área prospectada (Fig 1) advierte que no se debe descartar que el efecto borde podría estar influyendo los resultados (Wheatley \& Gillings 2002:209). Otras fuentes de recursos como agua, rocas y ocres podrían existir por fuera de estos límites y más cercanas a estas cuevas que las actualmente conocidas, y otros loci de actividades múltiples por fuera de estos límites permitirian trazar otros caminos principales y secundarios.

Otra opción para ampliar la muestra sería incluir sitios con arte realizado mediante otras técnicas de producción, como el grabado (por ejemplo el sitio Los Navarros, localizado $7,5 \mathrm{~km}$ al noroeste y Grabados de Laguna Cerro Bonete, 20,6 km al noreste). En ese caso, se estaría evaluando la decisión de dónde realizar arte, sin distinguir la técnica usada. En este caso además habría que discutir si dadas las posibles diferencias cronológicas que se han planteado para ambas técnicas en la región, conviene unificar las muestras, o analizarlas separadamente, tal vez buscando detectar cambios en las decisiones locacionales a través del tiempo. Al respecto, las cronologías adjudicadas a la técnica de grabado se han restringido a los últimos 2500 a 1500 años en sitios de lago Cardiel y lago Strobel, (Gradín 195960; Belardi \& Goñi 2002, 2006; Re \& Guichón 
2010), el área del río Pinturas y la meseta del lago Buenos Aires (Gradín 1976, 1979), así como para los grabados del macizo Central (Carden 2009). Aunque no se descarta que podría ser adjudicada a un lapso temporal mayor (Carden 2009; Belardi \& Goñi 2002, 2006; Goñi et al. 2004; Miotti 1991; Re et al. 2005).

Tal vez lo más conveniente sería realizar nuevas prospecciones para el relevamiento de cuevas y aleros sin arte pintado dentro de la localidad y volver a comparar las muestras. Dado que las prospecciones en la localidad se realizaron por medio de transectas con $1 \mathrm{~km}$ de separación entre sus trazados, es posible que existan cuevas no registradas en el territorio que aun no fue recorrido. Esta puede ser una solución viable, ya que la inclusión de una o dos cuevas más sin arte podrían permitir alcanzar la significancia estadística (Siegel \& Castellman 1995). Sumado a esto, si estas cuevas se encuentran ubicadas en lugares centrales, lejos de los bordes del área prospectada, podría lograrse la corrección parcial del problema del borde antes mencionado, haciendo más confiables a los datos.

Con los resultados obtenidos hasta ahora, a continuación se describen las tendencias en los datos, y cómo podrían tomarse en consideración en futuros análisis.

\section{Amplitud de cuencas visuales}

Las tendencias observadas en los datos sugieren que las cuevas con arte pueden tener cuencas visuales más amplias que las cuevas donde no está presente. En otros casos de estudio (por ejemplo Criado \& Viloch 1998; Watson 2001) se planteó que la existencia de cuencas visuales más amplias desde cuevas con arte puede estar indicando una asociación del arte con actividades de vigilancia para control de la movilidad de animales o grupos humanos en contextos de caza o defensa territorial. Por otro lado, además de una cuenca visual amplia, el plantear una situación de control o defensiva requiere de otros indicadores. Por ejemplo, que en el campo visual coincidan pasos o caminos frecuentemente usados por personas o animales, y que la condición de visibilidad del lugar donde se emplaza el punto de observación (donde se encuentra el arte) desde distintos puntos del paisaje, haga posible inferir estrategias de visibilización del arte rupestre (Criado 1993), denotando distinta intencionalidad y una construcción social del paisaje. Entonces, si bien aquí se cuantificó la amplitud de las cuencas visuales, un análisis de qué es concretamente lo que puede verse desde esas localizaciones puede ser de utilidad para continuar por esta línea de estudio. Podría seguirse la propuesta de Carden (2009) en esta localidad, quien plantea que la posibilidad de ver otros sitios con arte, ciertos hitos del paisaje, caminos o determinados recursos pudo incidir en la elección del lugar dónde realizar arte. Esto mismo podria testearse aplicando análisis de líneas de visión mediante SIG desde cada localización con arte rupestre para generar información cuantitativa y así realizar comparaciones en un marco metodológico formal mediante SIG.

\section{Distancias a recursos}

Con respecto a la distancia a recursos, el continuar investigando la tendencia registrada es interesante porque una menor distancia de las cuevas con arte a las fuentes de agua, las rocas útiles para la confección de artefactos líticos y los afloramientos de ocre permitiría plantear que el arte rupestre pudo ser una actividad realizada en relación con otras actividades domésticas (Aschero 1996, 1997) en un mismo circuito de movilidad (Binford 1979, Nelson 1991). Por otro lado, entre los recursos mencionados, el ocre es el único que está directamente relacionado con la producción de arte, aunque también pudo haber sido usado para preparación de pinturas corporales y el tratamiento de cueros (Carden 2009). La expectativa de que la localización de afloramientos de ocre en el paisaje haya sido un factor tomado en cuenta para el emplazamiento del arte rupestre ya fue planteada antes para esta región (Aschero 1997). Si los lugares elegidos para realizar pinturas rupestres fueron aquellas localizaciones cercanas a recursos de subsistencia como agua, rocas así como a fuentes de pigmentos, esto podría sugerir un grado de complementariedad o de similar importancia otorgada a la realización de actividades subsistencia y a la producción de arte en esos lugares. A su vez, esto refuerza la idea de arte rupestre como parte de contextos cotidianos, no segregados espacialmente de otras actividades (Aschero 1996, 1997). 
Es interesante que las distancias a las fuentes de ocres sean las máximas dentro de las analizadas (ver Tabla 2 y Fig. 4), y, como esto también sucede entre las cuevas sin arte, es posible interpretar que las fuentes de estos pigmentos son puntuales, menos abundantes y más dispersas en el espacio que los otros recursos. Desde la etnogrfía hay también evidencias que apuntan en el mismo sentido, ya que señalan la localización lejana del ocre usado para preparar pinturas en relación a los lugares residenciales de los grupos de cazadores-recolectores históricos. En la zona del río Pinturas, por ejemplo, las tizas o lápices se confeccionaban usando arcilla de colores proveniente de un manantial hallado en lo alto de un cañadón, alejado de donde residían los grupos tehuelches. La extracción de pigmentos se realizaba durante partidas especiales [...]era algo sagrado ir a buscar pintura[...] no podía ir cualquiera, era un lugar sagrado (Aguerre 2000:132).

\section{Distancias a redes de caminos teóricos}

La distancia de las cuevas con y sin arte al trazado de redes de caminos óptimos separados en dos jerarquías (principales y secundarios), podría ser una manera de abordar el estudio del arte en relación con la movilidad humana (ver Magnin 2010). Como la red de caminos fue trazada entre sitios interpretados como loci de actividades múltiples con posible función de campamentos base residenciales, la variable modelada en este caso pertenece a la esfera del medioambiente creado por el hombre, es decir, sería un factor que modela aspectos sociales del uso del espacio (Kvamme 2006:18).

Como fue planteado antes (Mangin 2010) la mayor cercanía de las cuevas con arte a las redes de caminos principales podría estar indicando su uso en relación con movimientos residenciales, y con actividades planificadas de antemano por estar dentro de la ruta de traslado frecuentemente recorridas. De manera opuesta, localizaciones más cercanas a caminos secundarios, podrían indicar que el uso de las cuevas con arte está asociado a actividades específicas de extracción o procesamiento de recursos. En este caso es posible plantear que las evidencias asociadas a caminos secundarios pueden relacionarse a tareas con objetivos concretos, no una actividad incorporada en una ronda que involucra diversas tareas (Binford 1982, Nelson 1991).
Si las cuevas con arte tienden a localizarse más cerca que las cuevas sin arte de la red de caminos tanto primarios como secundarios, esto podría indicar que estas redes de caminos fueron factores tomados en cuenta para elegir las cuevas donde realizar el arte. El emplazamiento del arte rupestre señalizando las vías de movilidad ha sido planteado antes en otros contextos, por ejemplo en los grabados rupestres de Galicia, aunque en ese caso los grabados marcarían las vías de movilidad naturales usadas por los animales (Criado 1993). En ese caso, el arte rupestre estaría emplazado en relación con recursos de subsistencia. En el área del macizo Central algo similar se planteó para el caso de los grabados realizados sobre bardas basálticas localizadas circundando lagunas temporarias que son concentradoras de recursos (agua, fauna y flora), como es el caso, Laguna del Cerro Bonete y La Leonera (Miotti et al. 1999), localizadas en otros sectores del macizo Central. En la localidad La Primavera el arte no aparece directamente localizado sobre los puntos geográficos donde ocurren naturalmente diversos recursos (por ejemplo, aguadas, lagunas, afloramientos de ocre o canteras de aprovisionamiento), sino en las cuevas y aleros cuyas distancias a esos recursos buscamos cuantificar en este trabajo. Una función del arte como manifestación de tenencia o reclamos de apropiación de recursos (Ingold 1986), en cambio, podría plantearse en esta localidad en relación a los refugios rocosos: las cuevas y aleros. Probablemente varios de estos sitios, como se ha comprobado en el caso de Cueva Maripe (Miotti et al. 2007), fueron concentradores de actividades humanas y de recursos naturales producto de las salidas logísticas. Por lo tanto, planteamos que el arte rupestre pudo haber sido usado como un signo para la apropiación de esos espacios reparados y con buenas condiciones de habitabilidad.

Por otro lado, la red de caminos trazados en el presente caso de estudio, modela las vías de menor coste entre loci de actividades múltiples, es decir que modela la movilidad humana (a diferencia del caso de estudio gallego que modela la movilidad de animales). En ese sentido, el estudio del emplazamiento del arte en relación con estos caminos podría informar acerca de posibles actividades de vigilancia y control de los movimientos de personas, o la demarcación simbólica de estos lugares (Miotti et al. 2007, Carden et al. 2009. 


\section{CONCLUSIÓN}

El análisis presentado es una forma de abordar las decisiones de localización en el paisaje vinculadas concretamente a la esfera del arte rupestre en la localidad La Primavera. A lo largo de 8500 años los grupos cazadores recolectores transitaron y ocuparon el paisaje moviéndose de un lugar a otro y tomando decisiones basadas en criterios ambientales, sociales y simbólicos. ¿Qué se puede aprender acerca de la producción de arte a partir del estudio de su emplazamiento en el paisaje? Este trabajo es una propuesta para comprender los patrones generales en las decisiones tomadas por aquellos grupos y que se plasman en la materialidad del arte rupestre, mostrando una metodología para plantear análisis exploratorios complementarios de otras líneas de evidencia que se han desarrollado de manera consistente (Carden 2009, Carden et al. 2011). También este aporte destaca otros caminos analíticos que se desprenden como pasos a seguir investigando. Si bien la pregunta del título no ha sido resuelta, constituye un avance para comenzar a cuantificar las decisiones tomadas e intentar diferenciar qué opciones tuvieron sus productores. Muchas otras decisiones además del emplazamiento en el paisaje están implícitas en la realización de arte rupestre. [...] La elección del sitio y la del soporte son dos decisiones previas a la imposición de una determinada forma de representación. Pero son elecciones que comprometen otras: la previsión de poder volver a verla, o de que sea vista por otros; la de que sea accesible o inaccesible al campo manual $y /$ o visual del futuro observador, la de que esté bien preservada para prolongar su vida útil (Aschero 1997:19). Si bien las motivaciones originales, atravesadas por dimensiones materiales, sociales y simbólicas, son inaccesibles para la investigación arqueológica, el esfuerzo debe orientarse a diseñar protocolos para aplicar sobre los datos para detectar patrones robustos. Como se destacó en el caso aquí analizado, la existencia de patrones aparentes en los datos requiere de un esfuerzo en su contrastación sobre el que es importante detenerse. Sin asumir que el hallazgo de patrones en la localización del arte rupestre define a las variables analizadas como la causa de las localizaciones (Wheatley 2004, Woodman \& Woodward 2002), un camino posible hacia el estudio de la toma de decisiones acerca de los motivos en la elección de ¿dónde pintar? es la descripción de la decisión tomada, frente a otras posibles. Esto requiere de cuantificación para lo cual los SIG brindan herramientas útiles.

Por último, La metodología usada aquí puede ser aplicada en otras áreas que presenten, al igual que en la localidad La Primavera, soportes aptos para realizar arte que no hayan sido utilizados.

\section{AGRADECIMIENTOS}

Beca post doctoral CONICET. Natalia Carden me alentó a realizar este trabajo, sugirió bibliografía y realizó valiosos aportes. Vanesa Bagaloni corrigió un borrador del manuscrito. Ramiro Sarandón brindó asesoramiento en temas de estadística.

\section{BIBLIOGRAFÍA}

Aguerre, A. (2000). Las vidas de Pati en la toldería tehuelche del Río Pinturas y después. Buenos Aires: Universidad de Buenos Aires, Facultad de Filosofía y Letras.

Arsenault, D. (2004). From natural settings to spiritual places in the Algonkian sacred landscape: an archaeological, ethnohistorical and ethnographic analysis of Canadian Shield rock art sites. En Chippindale, C \& Nash, G. (Eds.), The Figured Landscapes of Rock-Art. Looking at Pictures in Place. Cambridge: Cambridge University Press.

Aschero, C. (1988). Pinturas rupestres, actividades y recursos naturales: un encuadre arqueológico. En H. Yacobaccio (Ed.), Arqueología Contemporánea Argentina, Actualidad y Perspectivas. Buenos Aires: Ediciones Búsqueda.

Aschero, C. (1996). ¿Adónde van esos guanacos? En Gómez Otero, J. (Ed.), Arqueología. Solo Patagonia. Ponencias de las II Jornadas de Arqueología de La Patagonia. Puerto Madryn: CENPAT-CONICET.

Aschero, C. (1997). De cómo interactúan emplazamientos, conjuntos y temas. Revista del Museo de Historia Natural de San Rafael, XVI, 17-28.

Belardi J. B. \& L. A. Borrero (1999). El paisaje arqueológico de la margen norte del Lago Argentino (provincia de Santa Cuz). Praehistoria 3, 35-64.

Belardi, J. B. \& R. Goñi (2002). Distribución Espacial de Motivos Rupestres en la Cuenca del Lago Cardiel (Patagonia Argentina). Boletín de la SIARB 16, 29-38.

Belardi, J. B. \& R. Goñi (2006). Representaciones rupestres y convergencia poblacional durante momentos tardíos en Santa Cruz (Patagonia argentina). El caso de la meseta del Strobel. En: Fiore D. \& M. Podestá (Eds.), Tramas en la Piedra. Producción y usos del arte rupestre. Buenos 
Aires: Sociedad Argentina de Antropología, Asociación Amigos del Instituto Nacional de Antropología, World Archaeological Congress.

Belardi, J. B., Carballo Marina, F., Burlot; T., \& A. Re (2010). Paisajes arqueológicos, circulación e interacción en diferentes escalas: una perspectiva desde el lago Tar (provincia de Santa Cruz), En: M. Salemme, F. Santiago, M. Álvarez, E. Piana, M. Vázquez \& M. Mansur (Eds.), Arqueología de Patagonia: una mirada desde el último confín. Ushuaia: Editorial Utopías.

Binford, L. (1979 ). Organization and Formation Processes: Looking at Curated Technologies. Journal of Anthropological Research 35(3), 255-273.

Borrazo, K. (2004). Hacia una tafonomía lítica: el análisis tafonómico y tecnológico de los conjuntos artefactuales líticos de superficie provenientes de los loci San Genaro 3 y 4 (Bahía San Sebastián-Tierra del Fuego, Argentina). Licenciatura, Universidad Nacional de Buenos Aires.

Borrero, L.A. (1995). Historia reciente de la Arqueología Patagónica. Runa XXII, 151-176.

Borrero, L.A. (2001). Regional Taphonomy: Background noise and the integrity of the archaeological record. En: L. Kuznar (Ed.), Contributions to Archaeological Method and Theory. Ann Arbour: International Monographs in Prehistory, Ethnoarchaeological Series 4.

Borrero, L. A.; J. L. Lanata \& B. Ventura (1992). Distribuciones de hallazgos aislados en Piedra del Águila. En: L. Borrero \& J.L. Lanata (Eds.), Análisis Espacial en la Arqueología Patagónica. Buenos Aires: Ayllu.

Bosque Sendra, J. \& M. Gómez Delgado (2007). Validación de análisis realizados con Sistemas de Información Geográfica. En: Memorias XI Conferencia Iberoamericana de Sistemas de Información Geográfica., Luján: SIBSIG-UNLU.

Bradley, R., Criado Boado, F. \& R. Fabregas (1995). Rock Art Research as Landscape Archaeology: A Pilot Study in Galicia, North-West Spain. World Archaeology, 25(3), 374-390.

Butzer, K. (1989). Arqueología, una ecología del hombre: Método y teoría para un enfoque contextual. Barcelona: Bellaterra.

Carden, N. (2009). Imágenes a través del tiempo. Arte rupestre y construcción social del paisaje en la Meseta Central de Santa Cruz. Buenos Aires: Sociedad Argentina de Antropología.

Carden, N. (2010). El Arte Rupestre de la Patagonia: ¿Expresión de Ideas o Materialización de Actividades? En: Actas del VIII Simposio de Arte Rupestre. San Miguel de Tucumán: Instituto Superior de Estudios Sociales, Consejo
Nacional de Investigaciones Cientificas y Tecnicas/UNT (ISES, CONICET, UNT).

Carden, N., Magnin, L. \& L. Miotti (2009). Distribución de figuras animales y dinámica poblacional: un estudio comparativo en Patagonia (provincia de Santa Cruz). En: Sepúlveda M., L. Briones \& J. Chacama (Eds.), Crónicas sobre la Piedra. Arte rupestre de las Américas. Arica: Ediciones Universidad de Tarapacá.

Carden, N., Blanco, R., Poiré, D.; Magnin, L., Genazzini, C.; \& P. García (2011). Análisis DRX en pigmentos de la Localidad La Primavera (Santa Cruz, Argentina): Hacia una contextualización espacio-temporal de la producción del arte rupestre. En: Libro de Resúmenes de las VIII Jornadas de Arqueología de la Patagonia, Malargüe.

Conolly, J. \& M. Lake (2006). Geographical Information Systems in Archaeology. Cambridge: University Press.

Criado Boado, F. (1993). Visibilidad e interpretación del registro arqueológico. Trabajos de Prehistoria 50, 39-56.

Criado Boado, F. (1999). Del terreno al espacio: planteamientos y perspectivas para la Arqueología del Paisaje. CAPA $6,1-58$.

Criado Boado, F. \& V. Villoch Vázquez (1998). La monumentalización del paisaje: percepción y sentido original en el megalitismo de la Sierra de Barbanza (Galicia). Trabajos de Prehistoria 55(1), 63-80.

Ebert, J. (2000). The State of the Art in "Inductive" Predictive Modeling. Seven Big Mistakes (and Lots of Smaller Ones). En: Practical Applications of GIS for Archaeologists. A Predictive Modeling Toolkit.Editado por: Wescott, Konnie \& Brandon, R. Londres.

ESRI (2010). ArcGIS Desktop: Release 10. SP 1. Build 2800 Level: Advanced (ArcInfo). California: Redlands.

Fábrega Álvarez, P. \& C. Parcero Oubiña (2007). Proposals for an archaeological analysis of movement and pathways. Archeologia e Calcolatori 18, 121-140.

Favier Dubois, C. (2001). Análisis geoarqueológico de los procesos de formación del registro, en sitios arqueológicos de Fuego-Patagonia. Doctorado, Universidad Nacional de Buenos Aires.

Fiore, D. \& Hernández Llosas M.I. (2007). Miradas rupestres. Tendencias en la investigación del arte rupestre parietal en Argentina. Relaciones de la Sociedad Argentina de Antropología, XXXII, 217-242.

Fiore, D. \& M. Ocampo (2009). Arte rupestre de la región Margen Norte del Río Santa Cruz: una perspectiva distribucional. En: M. Salemme, F. Santiago, M. Álvarez, E. Piana, M. Vázquez \& M. Mansur (Eds.), Arqueología de Patagonia: una mirada desde el último confín. Ushuaia: Utopías.

Foley, R. (1981). A model of Regional Archaeological Structure. 
Proceedings of the Prehistoric Society 47, 1-17.

Franco, N. \& L. A. Borrero (1996). El stress temporal y los artefactos líticos. La cuenca superior del río Santa Cruz. En: Gómez Otero J. (Ed.), Arqueología, sólo Patagonia. Puerto Madryn: CENPAT-CONICET.

Gamble, C. (1990). El Poblamiento Paleolítico de Europa. Barcelona: Crítica.

Gaffney, V., Z. Stancic \& H. Watson (1996). Moving from catchments to cognition: Tentative steps toward a larger archaeological context for GIS. En: Aldenderfer, M. \& H. D. G. Maschner (Eds.), Anthroplogy, Space and Geographic Information Systems. Oxford: Oxford University Press.

Gómez, J. \& L. Magnin (2006). Geomática aplicada en arqueología de Cazadores Recolectores. Localización del recurso crítico: agua. Santa Cruz (Argentina). En: Libro de Resúmenes del V Reunión Nacional de Ciencias de la Tierra, Puebla.

Goñi, R., J. B. Belardi, S. Espinosa \& F. Savanti (2004). Más vale tarde que nunca: cronología de las ocupaciones cazadoras recolectoras en la cuenca del lago Cardiel (Santa Cruz, Argentina). En: M.T. Civalero, P. Fernández \& A. G. Guráieb (Eds.), Contra Viento y Marea. Arqueología de la Patagonia. Buenos Aires: INAPL-SAA.

Gradin, C. (1959-60). Petroglifos de la meseta del lago Strobel (Provincia de Santa Cruz, Argentina) Acta Praehistorica, 3/4: 23-143.

Gradin, C. (1976). Parapetos de piedra y grabados rupestres en la meseta del lago Buenos Aires. Revista Museo Historia Natural de San Rafael, I, 315-337.

Gradin, C. (1989). Los grabados rupestres del Cerro Yanquenao en la provincia del Chubut. Rawson: Gobierno de la Provincia del Chubut.

Hyder, W. (2004). Locational analysis in rock-art studies. En: Chippindale, C \& Nash, G. (Eds.), The Figured Landscapes of Rock-Art. Looking at Pictures in Plac. Cambridge: Cambridge University Press.

Ingold, T. (1986). The appropriation of nature. Essays of human ecology and social relations. Manchester: Manchester University Press.

Ingold, T. (1993). The Temporality of Landscape. World Archaeology 25, 152-74.

Judge, W. \& L. Sebastian eds. (1988). Quantifying the Present and Predicting the Past: Theory, Method and Application of Archaeological Predictive Modeling. Washington: US Bureau of Land Management, Department of Interior, US Government Printing Office.

Krist, F.J. (2006). Multi-criteria/multi-objective predictive modeling: a tool for hunter-gatherer desition making and behavior. En: Mehrer, Mark W. \& K.L. Wescott (Eds.), GIS and Archaeological Site Location Modeling. Nueva York: CRS Press.

Krist, F. \& Brown, D. (1994). GIS modeling of Paleo-Indian period caribou migrations and viewsheds in Northeastern Lower Michigan. En: Photogrammetric Engineering and Remote Sensing, 60(9), 1129-1137.

Kvamme, K. (1988). Development and testing of quantitative models. En: Quantifying the Present and Predicting the Past: Theory,Method and Application of Archaeological Predictive Modeling. Washington: US Bureau of Land Management, Department of Interior, US Government Printing Office.

Kvamme, K. (2006). There and Back Again: Revisiting Archaeological Location Modeling, En: M.W. Mehrer \& K. Wescott (Eds.), GIS and Archaeological Predictive Modeling. Boca Raton: CRC-Taylor and Francis.

Lenssen-Erz, T. (2004). The landscape setting of rock-painting sites in the Brandberg, Namibia: infrastructure, Gestaltung, use and meaning, En: Chippindale, C \& Nash, G. (Eds.), The Figured Landscapes of Rock-Art. Looking at Pictures in Place. Cambridge: Cambridge University Press.

Llobera, M. (1996). Exploring the topography of mind: Gis, social space and archaeology. Antiquity 70, 612-622.

Magnin, L. (2006). Informe de Avance de Beca Interna y Solicitud de renovación de Beca Interna de Posgrado tipo I, CONICET, período informado: Abril 2005 / Octubre 2006. MS.

Magnin, L. (2008). Informe de campaña de prospección realizada en la Localidad Arqueológica la Primavera entre el 27 de Enero y el 25 de Febrero 2008. Presentado ante la Municipalidad de Pico Truncado, Santa Cruz. MS

Magnin, L. (2009). Paisajes digitales. Aproximación teórica, materiales y técnicas. En: M. Salemme, F. Santiago, M. Álvarez, E. Piana, M. Vázquez y M.E. Mansur (Eds.), Arqueología de Patagonia: una mirada desde el último confín. Ushuaia: Editorial Utopías.

Magnin, L. (2010). Distribuciones arqueológicas en la Meseta Central de Santa Cruz. Implicancias para los estudios del uso del espacio y movilidad de sociedades cazadoras-recolectoras. Doctorado, Universidad Nacional de La Plata.

Magnin, L. (2011). Las variables locacionales en estudios de emplazamiento mediante SIG, En: Libro de Rresúmenes del IV Congreso Argentino de Arqueometría, UNLu, Luján.

Martínez Bea, I. (2006). Arte rupestre y SIG en los alrededores de Santonela. En: Grau Mira, I. (Ed.), La aplicación 
de los SIG en la arqueología del paisaje. Alicante: Universidad de Alicante.

Mazzoni, E. (2007). Geomorfología y evolución geomorfológica de los escoriales volcánicos y sus mallines asociados en diferentes ambientes de Patagonia extra-andina. Doctorado, Universidad Nacional del Sur, Bahía Blanca.

Mineria (2012). http://www.mineria.gov.ar/estudios/irn/ santacruz/z-4b.asp, último acceso 13/04/2012.

Miotti, L. (1998). Zooarqueología de la meseta central y costa de Santa Cruz. Un enfoque de las estrategias adaptativas aborígenes y los paleoambientes. Mendoza: Museo Municipal de Historia Natural de San Rafael.

Miotti, L. (1991). Manifestaciones rupestres de Santa Cruz: La localidad Arqueológica Piedra Museo. En: Podestá, M.; M.I. Hernández Llosas \& S. Renard de Coquet (Eds.), El Arte Rupestre en la Arqueología Contemporánea. Buenos Aires: FECIC.

Miotti, L; N. Carden \& M. J. Canosa (1999). Paisajes arqueológicos de Cazadores-recolectores, Arte rupestre y Lagunas. En: C. Diez Marín (Ed.), Actas del XII Congreso Nacional de Arqueología Argentina. La Plata: Universidad Nacional de La Plata.

Miotti, L.; N. Carden \& L. Magnin (2007). Tendencia central, dispersión y orientación en el paisaje regional. Estudios de distribución del arte rupestre en la Meseta Central de Santa Cruz. En: Morello F., M. Martinic, A. Prieto \& G. Bahamonde (Eds.), Arqueología de Fuego-Patagonia. Levantando piedras, desenterrando huesos... y develando arcanos. Punta Arenas: Ediciones CEQUA.

Nelson, M. (1991). The Study of Technological Organization, En: M. Schiffer (Ed.), Archaeological Method and Theory. Tucson: Arizona Press.

Panza, J. L. (2001). Hoja Geológica 4769-IV, Monumento Natural Bosques Petrificados, Provincia de Santa Cruz. En: Dirección Nacional del Servicio Geológico, Boletín 258. Buenos Aires: Servicio Geológico Minero Argentino.

Re, A. \& F. Guichón (2010). Densidad y distribución de representaciones rupestres en la meseta del Strobel (Provincia de Santa Cruz). En: M. Salemme, F. Santiago, M. Álvarez, E. Piana, M. Vázquez y M.E. Mansur (Eds.), Arqueología de Patagonia: una mirada desde el último confín. Ushuaia: Editorial Utopías.

Re, A., Nuevo Delaunnay, A., \& L. Ferraro (2005). Grabados en la Meseta del Lago Strobel (Santa Cruz, Argntina). Sitio laguna del Faldeo Verde. Relaciones XXX, 245-256.

Ridges, M. (2006). Regional Dynamics of Hunting and Gathering: An Australian Case Study Using Archaeological Predictive Modeling. En: Mehrer, Mark W. y Konnie L. Wescott, Taylor \& Francis Group (Eds.), GIS and
Archaeological Site Location Modeling. Nueva York: CRS Press.

Ross, J.; Valenzuela D.; Hernández Llosas, M. I.; Briones, L., \& Santoro, C. (2008). More than the motifs: the archaeological analysis of rock art in arid regions of the Southern Hemisphere. Chungara Revista de Antropología Chilena, 40, 273-294.

Rossignol J. \& L.Wandsnider eds. (1992). Space, Time and Archaeologycal Landscapes. New York: Plenum Press. Scheinsohn, V., S. Zumik, C., Rizzo, F. \& Leonardt, S. (2011). La localidad de Río Pico (Chubut) en el marco de los patrones distribucionales del arte rupestre en el Norte de Patagonia. En: Libro de resúmenes de las VII Jornadas de Arqueología de la Patagonia, Ushuaia.

Schobinger, J. (1956). El Arte Rupestre de la provincia del Neuquén. Anales de Arqueología y Etnología XII, 115-227.

Schobinger, J. \& C. Gradin (1985). Arte Rupestre de la Argentina. Cazadores de la Patagonia y Agricultores Andinos. Madrid: Ediciones Encuentro.

Siegel S. \& N.Castellman (1995). Estadística no paramétrica aplicada a ciencias de la conducta. México: Trillas.

Silversten, B. (1980). A site activity model for Hill and butchering activities at hunter-gatherer sites. Journal of field Archaeology 7, 423-442.

Tilley, C. (1994). A Phenomenology of Landscape: Places, Paths and Monuments. Oxford: Berg Publishers.

Tobler, R. (1993). Three presentations on geographical analysis and modelling: Non-isotropic analysis and modelling. Non-isotropic geographic modelling. Speculations on the geometry of geography global spatial analysis. En: Technical report 93-1, Santa Barbara National Center of Information and Analysis.

Van Leusen, M. (1996). GIS and Locational Modeling in Dutch Archaeology: a Review of Current Approaches. En: Maschner, H. (Ed.), New Methods, Old Problems. Geographic Information Systems in Modern Archaeological Research. Carbondale: Occasional Paper 23, Centre of Archaeological Investigations, Southern Illinois University.

Van Leusen, M. (2002). Pattern to Process: Methodological Investigation and Interpretation of Spatial Patterns in Archaeological Landscapes. Doctorado, Universidad de Groningen.

Veregin, H. (1997). Data quality parameters. En: Longley, P. \& B. Michael (Eds.), Spatial Analysis: Modeling in GIS Environment. New York: John Wiley and Sons.

Waters, M. (1992). Geoarchaeological foundations. Principles of Geoarchaeology. Tucson: The University of Arizona Presss.

Waters, M. \& D. Kuehn (1996). The Geoarchaeology of Place: 
the effect of geological processes on the preservation and interpretation of the archaeological record. American Antiquity, 61(3), 483-497.

Watson, A. (2001). Composing Avebury. World Archaeology 33(2), 296-314.

Wheatley, D. (2004). Making space for an archaeology of place. Internet archaeology, 15:1-16 (http://www. inarch.ac.uk/).
Wheatley, D., \& M. Gillings (2002). Location models and prediction. En: Spatial Technology and Archaeology. Viena: Taylor and Francis.

Woodman, P. \& M. Woodward (2002). The use and abuse of statistical methods in archaeological site location modelling. En: D, Wheatley, G. Earl, \& S. Poppy (Eds.), Contemporary Themes in Archaeological Computing. Oxford: Oxbow Books. 